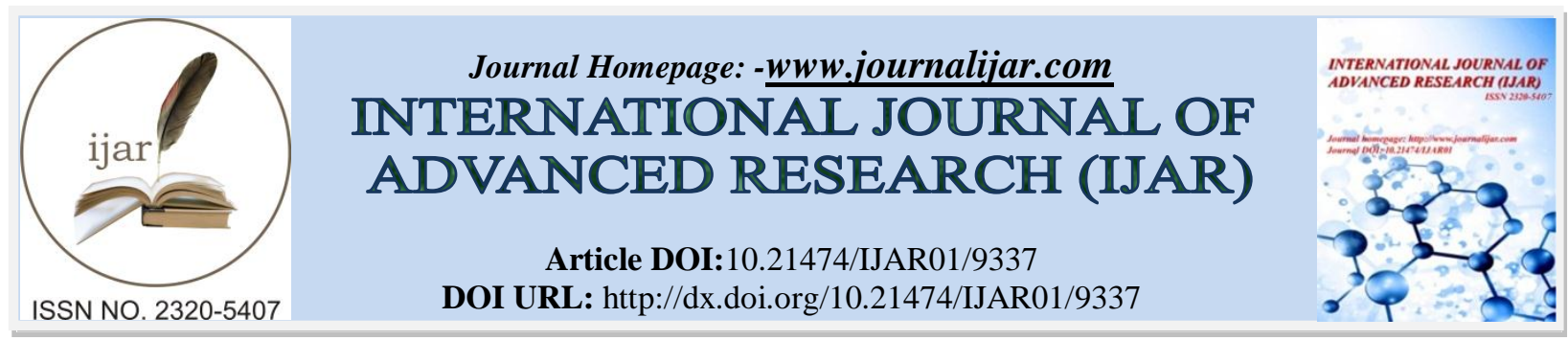

RESEARCH ARTICLE

\title{
EFFICACY AND SAFETY OF AZILSARTAN COMPARED WITH TELMISARTAN IN HYPERTENSIVE PATIENTS.
}

Lenka D.N. ${ }^{1}$ and Routray S.N. ${ }^{2}$.

1. Senior Resident, Dept. of Cardiology, S.C.B.Medical College. Cuttack, Odisha, India.

2. Professor, Dept. of Cardiology, S.C.B.Medical College. Cuttack, Odisha, India.

\section{Manuscript Info}

Manuscript History

Received: 04 May 2019

Final Accepted: 06 June 2019

Published: July 2019

Key words:-

Blood Pressure, Azilsartan, Telmisartan.

\section{Abstract}

Objective: Angiotensive receptor blockers (ARBs) are very potent antihypertensive agents, Telmisartan being the prototype and most widely used.This study was undertaken to compare the efficacy and safety of Azilsartan a new ARB with Telmisartan.

Material and methods : This prospective study was carried out in patients attending the Department of Medicine, SCB Medical college, Cuttack. Patients with newly diagnosed with stage I-II essential hypertension of either sex within the age group of 18-65 years with blood pressure of $\geq 140 / 90 \mathrm{mmHg}$ were included in the study. Severe hypertension $>180 / 110 \mathrm{~mm}$ of $\mathrm{Hg}$, hypersensitivity to ARBs, secondary hypertension with any other etiology, pregnant women, history of Drug/ Alcohol abuse, cardiac arrhythmias were excluded. Patients who gave consent for the study were divided into 2 random groups 1 and $2-$ the first received azilsartan and the second received telmisartan. Point of control was defined as blood pressure<140/90 $\mathrm{mm}$ of $\mathrm{Hg}$ after initiation of therapy.

Results : 180 patients were randomized into two groups. Out of 90 patients included in group 1 who received azilsartan, 4 lost for follow up. Out of 90 patients included in group 2 who received telmisartan, 5 lost for follow up. There was no significant difference between the two drugs in both mean systolic and diastolic blood pressure at 24hrs, 1 month and 3 months and 6 months. Mean diastolic blood pressure at 24 hrs was reduced more with telmisartan compared to azilsartan which is significant. Hypotension related adverse effects occurred in $3 \%$ of the patients in azilsartan group while it occurred in $8 \%$ of them in telmisartan group.

Conclusion: Azilsartan is an effective blood pressure lowering drug with its safety and efficacy comparable to that of telmisartan.

Copy Right, IJAR, 2019,. All rights reserved.

\section{Introduction:-}

Hypertension is defined as either a systolic blood pressure of $\geq 140 \mathrm{~mm} \mathrm{Hg}$ or a sustained diastolic blood pressure of $\geq 90 \mathrm{~mm} \mathrm{Hg}$, according to Joint National committee (JNC VIII) on hypertension. 
Although many patients may not have symptoms but chronic hypertension can lead to heart disease and stroke, the top two causes of death in the world. Hypertension is also an important risk factor in the development of chronic kidney disease. ${ }^{1}$

Effective control of blood pressure in patients with hypertension is required to produce a maximum reduction in clinical cardiovascular events ${ }^{2,3}$ and expert consensus guidelines advocate BP levels $<140 / 90 \mathrm{~mm}$ of $\mathrm{Hg}$ in patients lacking target organ involvement and $<130 / 80$ of $\mathrm{mmHg}$ in patient with diabetes mellitus, heart disease, or kidney disease ${ }^{4,5}$.

Angiotensin II appears to exert a central role in both the pathophysiology of essential hypertension and arteriosclerosis- associated hypertension ${ }^{6}$ and insulin resistance ${ }^{7}$.

Angiotensin receptor blockers are selective blockers of angiotensin receptors and are more potent than angiotensin converting enzyme(ACE) inhibitors ${ }^{8}$. ARBs are better tolerated with lesser side effects.

Among the angiotensin receptor blockers telmisartan has favourable pharmacokinetic profile, has longest plasma half-life and is the commonly prescribed ARB. US Food and Drug Administration (FDA) has approved azilsartan medoxomil as the 8 th ARB for the treatment of hypertension ${ }^{9}$.

Azilsartan was discovered by modifying the tetrazole ring present in candesartan ${ }^{10,11}$. Azilsartan has been shown to be effective in reducing BP when administered orally as either the ester prodrug azilsartan medoxomil or as the primary compound ${ }^{12-14}$.

The aim of this study was to compare safety and efficacy of newer ARB Azilsartan with Telmisartan.

\section{Material And Methods:-}

This Prospective, randomized open labelled parallel study was carried out in patients attending the Out-Patient and In-patient Department of Health care institute \& research centre ,Cuttack,Odisha.

\section{Inclusion criteria:}

Patients newly diagnosed with stage I \& II essentialhypertension of either sex within the age group of 18-65 years with blood pressure of $\geq 140 / 90 \mathrm{mmHg}$ were included in the study.

The upper limit of blood pressure in both groups was $179 / 109 \mathrm{mmHg}$. Only newly diagnosed hypertensive patients without prior antihypertensive treatment and without any associated diseases were included.

\section{Exclusion criteria :}

Severe hypertension $\geq 180 / 110 \mathrm{~mm}$ of $\mathrm{Hg}$, hypersensitivity to ARBs, secondary hypertension with any other etiology, history of Drug/Alcohol abuse, cardiac arrhythmias(atrial flutter, atrial fibrillation, ventricular tachycardia), Patients with sinus bradycardia, Sick sinus syndrome, Prinzmetal's angina, Heart block, Chronic heart failure, Myocardial infarction, Peripheral vascular disease, pregnant and lactating women, patients with impaired kidney function test confirmed by serum creatinine level $>2 \mathrm{mg} / \mathrm{dl}$, patients with impaired liver function test such as SGPT or SGOT > 2 times than normal limit, patients with asthma.

180 patients who were willing to participate and give informed consent and fulfilled inclusion and exclusion criteria were enrolled in the study. Patients were randomly divided into 2 groups by computer generated numbers. Group 1 received AZILSARTAN $40 \mathrm{mg}$ to $80 \mathrm{mg}$ daily and Group 2 received TELMISARTAN $40 \mathrm{mg}$ to $80 \mathrm{mg}$ daily depending on the initial blood pressure.

Standard Conventional sphygmomanometer was used for BP measurement and the pressure at which the korotokoff sounds were first heard was taken as the systolic pressure and the pressure at which the sounds disappeared was taken as the diastolic pressure. Two recordings of blood pressure were taken at an interval of $15 \mathrm{~min}$ in sitting position. After initial screening, the demographic data, past medical history, family history, findings of physical examination, and clinical examination were recorded in the case report form and following investigations were done. ECG,X-ray chest PA view,CBC,Blood urea,creatin,LFT,FBS,2 hr PPBS,Serum electrlytees , urine RM \& micral exam. 
Selection of patients was restricted to those who had a BP of $\geq 140 / 90 \mathrm{~mm}$ of $\mathrm{Hg}$ to $<180 / 110 \mathrm{~mm}$ of $\mathrm{Hg}$ (stage I and stage II hypertension).

Telmisartan was started at a dose of $40 \mathrm{mg}$ to 80 daily while Azilsartan was started at a dose of 40 to $80 \mathrm{mg}$ daily depending on the blood pressure.

Point of control was defined as blood pressure $<140 / 90 \mathrm{~mm}$ of $\mathrm{Hg}$ after initiation of therapy.They were followed up at the end of $1,3 \& 6$ month.

Adverse Drug reaction(ADR) monitoring :

The ADRs related to Azilsartan and Telmisartan were monitored and documented in suitably designed ADR documentation form after initial notification of the suspected ADR by physicians.

Causality of the ADRs were assessed by using Naranjo's Algorithm.

\section{Statistical analyses:-}

The primaryend point for assessing efficacy was the change from baseline in mean systolic and diastolic BP after 8 weeks of treatment.

Data were entered in MS excel 2007, same were exported into STATA (version 10). For normally distributed continuous data, comparison for significance of difference were done by using 1) Student's paired $t$ test for within group before and after treatment. 2) Student's unpaired t test was used for comparison of normally distributed continuous data between the two treatment groups. $P$ value $<0.05$ was considered statistically significant.

\section{Results:-}

This study was carried in the 180 patients were randomized and divided into two groups of 90 each. Group 1 received 40 to $80 \mathrm{mg}$ of Azilsartan and Group 2 received 40 to $80 \mathrm{mg}$ of Telmisartan (figure 1).

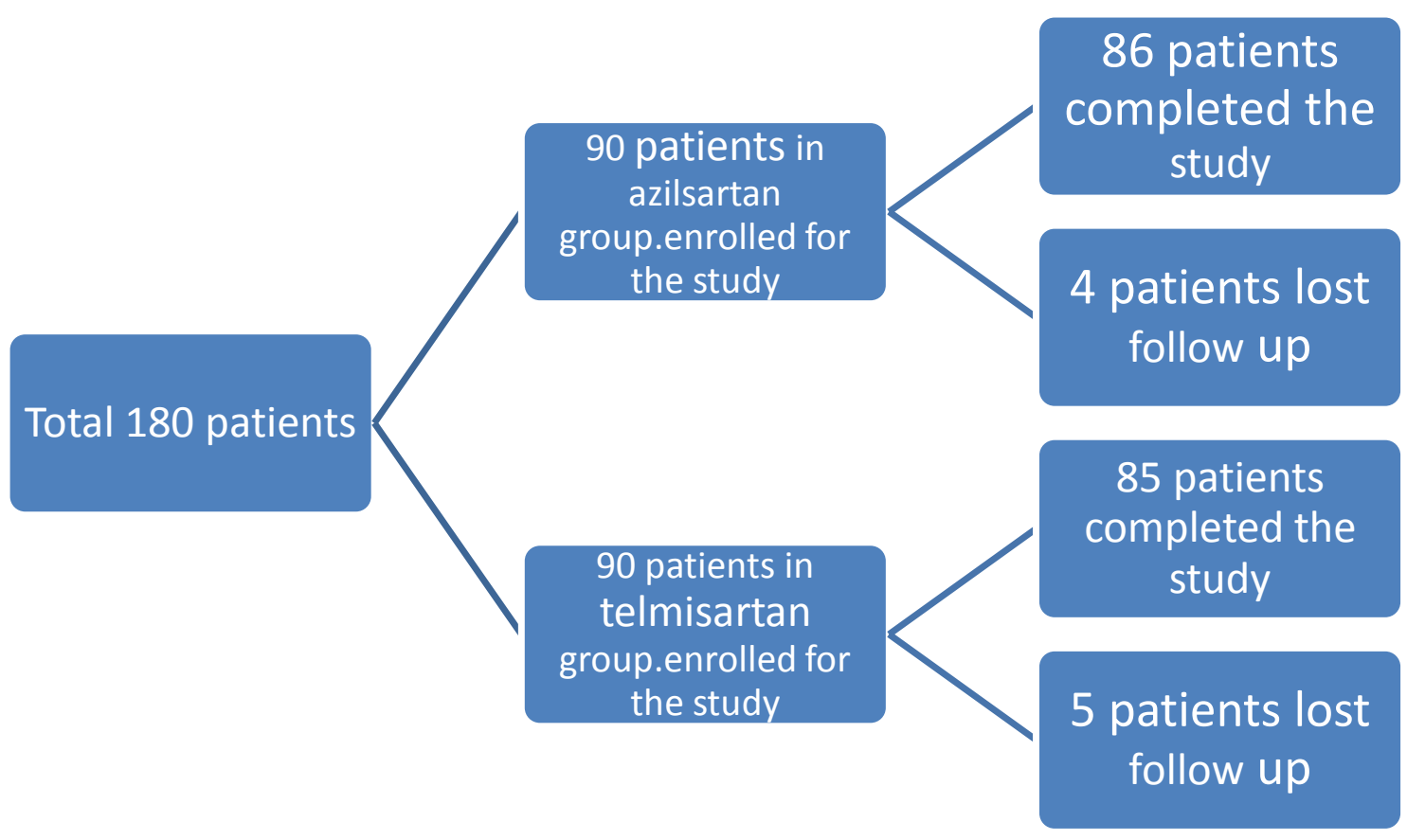

Figure 1:-Number of patients in both groups 
Effect of Telmisartan on blood pressure

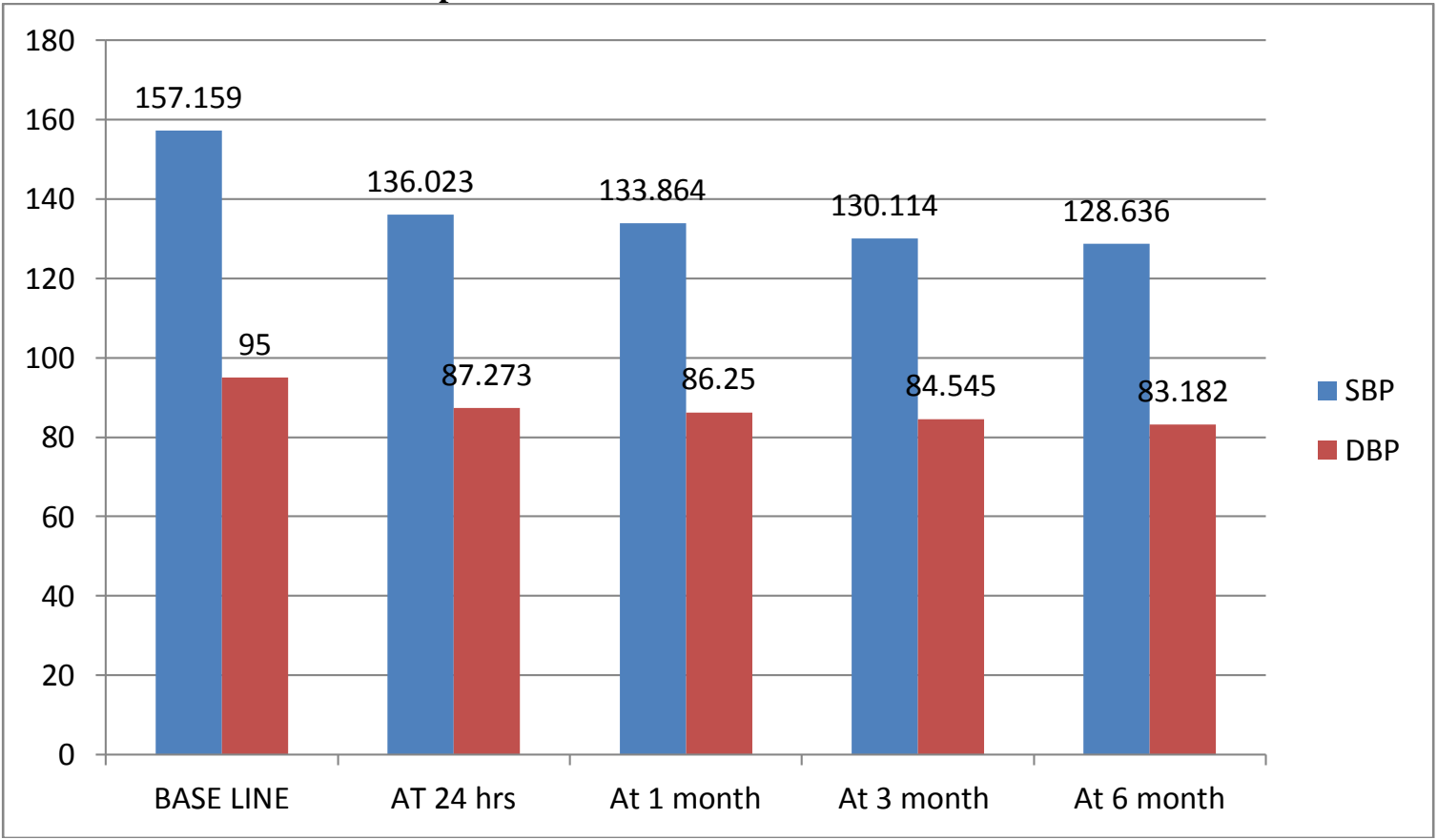

Figure 2:-Effect of Telmisartan on blood pressure

\section{Effect of Azilsartan on blood pressure}

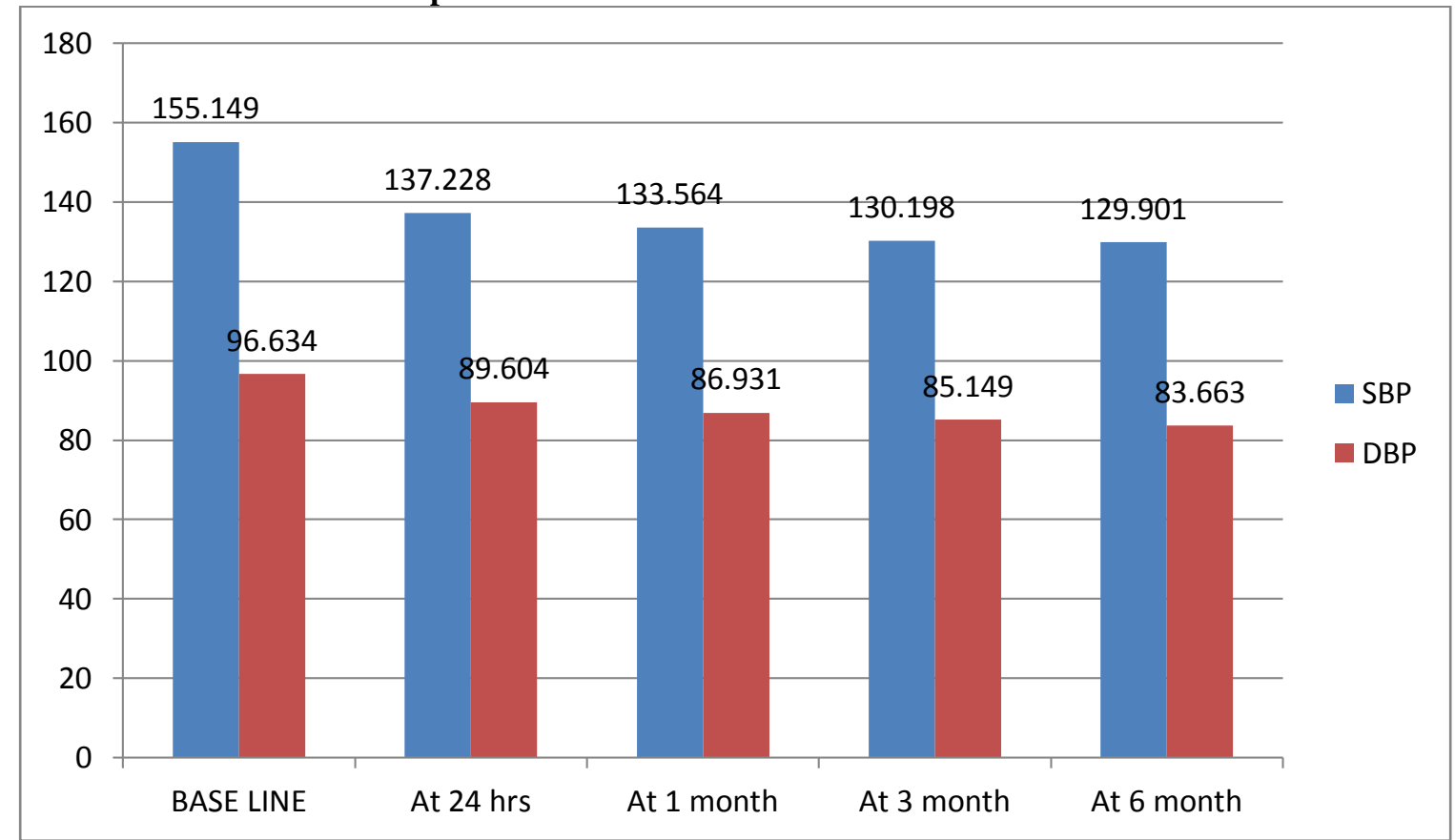

Figure 3:-Effect of Azilsartan on blood pressure 
Comparison between the two drugs

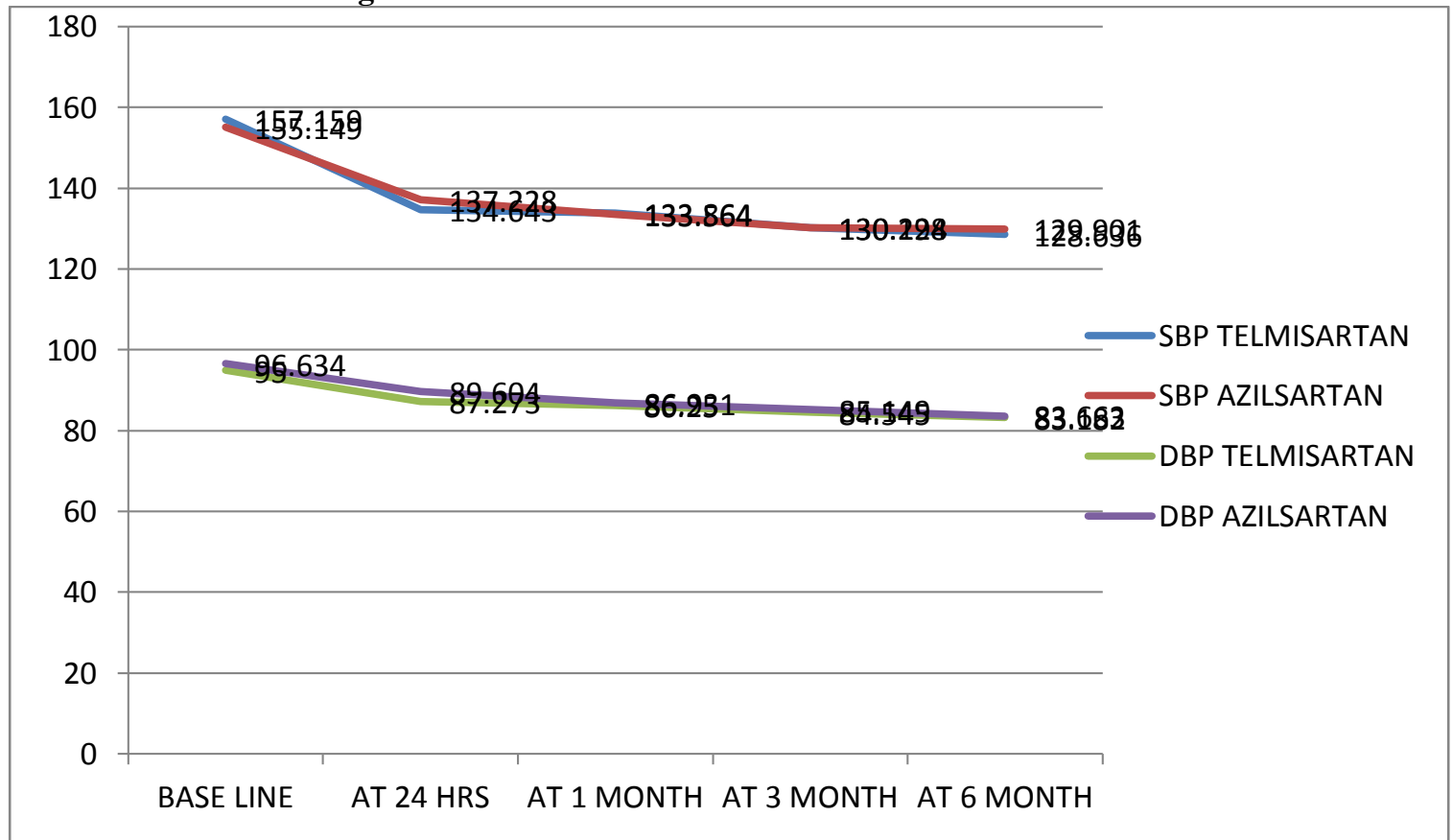

Figure 4:-Comparison between the two drugs

In Telmisartan group, at baseline mean systolic blood pressure was $161.72 \pm 12.35$, and at the end of the study mean systolicblood pressure was $132.36 \pm 9.41$ (systolic blood pressure was reduced by $29.36 \pm 4.12 \mathrm{~mm}$ of $\mathrm{Hg}$ ). Mean diastolic blood pressure was decreased from $99.3 \pm$ to 9.42 to $87.06 \pm 8.59$ (diastolic blood pressure was reduced by $11.11 \pm 2.058 \mathrm{~mm}$ of $\mathrm{Hg}$ ). There was a significant reduction in both systolic and diastolic blood pressure $(\mathrm{P}$ value $<0.001$ ) (figure 2).

In Azilsartan group, mean systolic blood pressure at baseline was $160.54 \pm 11.37$, and at the end of the study mean systolic blood pressure was $134.57 \pm 8.22$ (systolic blood pressure was decreased by $25.97 \pm 3.92 \mathrm{~mm}$ of $\mathrm{Hg}$ ). Mean diastolic blood pressure at baseline was $96.68 \pm 8.67$ and mean diastolic blood pressure at the end of the study was $86.62 \pm 5.52$ (diastolic blood pressure decreased by 10.06). There was a significant reduction in blood pressure.(P value $<0.001$ ) (figure-3).

Monotherapy with azilsartan $40 \mathrm{mg}$, to $80 \mathrm{mg}$ daily has been compared with telmisartan $40 \mathrm{mg}$ to $80 \mathrm{mg}$ daily. There was no significant difference between the two drugs in both mean systolic and diastolic blood pressure at 1 month, 3 month and 6 month. Mean diastolic blood pressure at 24 hrs was reduced more with telmisartan compared to azilsartan $(\mathrm{P}$ value $=0.011)$ which was statistically significant (figure-4).

The most common adverse effects occurring in 3\% of the patients in the Azilsartan group were rashes, and in 3\% were hypotension related events (dizziness, dizziness postural, syncope, vertigo and vertigo positional), whereas in telmisartan group dizziness, postural syncope and vertigo were observed in nearly $8 \%$.

\section{Discussion:-}

Azilsartan a newer angiotensin receptor blocker has shown cardiovascular benefits of lowering blood pressure in preclinical as well as clinical trials. These benefits are due to its property of high affinity to and slow dissociation from AT1R. In clinical trials, antihypertensive therapy has been associated with reductions in (1) stroke incidence, averaging $35-40 \%$; (2) myocardial infarction (MI), averaging 20-25\%; and (3) HF, averaging $>50 \%{ }^{15}$.

Azilsartan in clinically approved doses as azilsartan medoxomil has demonstrated to lower 24-hour BP in hypertensive patients significantly more than the maximumapproved dose of olmesartan medoxomil, the later being considered by some to be one of the most potent ARBs for lowering $\mathrm{BP}^{16-18}$. 
In the present study we observed that Monotherapy with azilsartan is equally efficacious to telmisartan given once daily in reducing mean blood pressure, by using mean systolic BP and mean diastolic BP monitoring at 8 weeks as primary efficacy end point. Telmisartan has shown slightly greater reduction in diastolic blood pressure at 24 hours.

Other studies have demonstrated superior efficacy and safety of azilsartan over routinely used ARBs but we observed patients who complained of rashes $(3 \%)$ required discontinuation of azilsartan.

There were no remarkable findings of clinical concern in laboratory test results, vital signs, body weight and 12-lead electrocardiogram findings.

\section{Conclusion:-}

Azilsartan, a newer angiotensin receptor blocker is an effective and safe blood pressure lowering drug. Its efficacy is comparable to that of telmisartan with additional benefit of lesser side effects and hence can be safely used in all the patients.

\section{Bibliography:-}

1. Whalen Karen, Richard Finkel, and Thomas A. Panavelil. Lippincots illustrated reviews: Pharmacology. Sixth edition. Philadelphia: Wolters Kluwer, 2015 pg. no:225.

2. Staessen JA, Wang JG, Thijs L. Cardiovascular protection and blood pressure reduction: a meta-analysis. Lancet. 2001;358:1305-1315.

3. Turnbull F, for the Blood Pressure Lowering Treatment Trialists' Collaboration. Effects of different bloodpressure-lowering regimens on major cardiovascular events: results of prospectively designed overviews of randomized trials. Lancet. 2003;362:1527-1535.

4. Chobanian AV, Bakris GL, Black HR, Cushman WC, Green LA, Izzo JL Jr, Jones DW, Materson BJ, Oparil S, Wright JT Jr, Roccella EJ, for the Joint National Committee on Prevention, Detection, Evaluation, and Treatment of High Blood Pressure. National Heart, Lung, and Blood Institute; National High Blood Pressure Education Program Coordinating Committee. Seventh report of the Joint National Committee on Prevention, Detection, Evaluation and Treatment of High BP. Hypertension. 2003; 42:1206-1252.

5. European Society of Hypertension-European Society of Cardiology Guidelines Committee. 2003 European Society of Hypertension European Society of Cardiology guidelines for the management of arterial hypertension. J Hypertension. 2003; 21:1011-1054.

6. Schmidt-Ott K. M., Kagiyama S., Phillips M. I. The multiple actions of angiotensin II in atherosclerosis. Regul. Pept. 2000;93, 65-77.

7. Olivares-Reyes J. A., Arellano-Plancarte A., Castillo- Hernandez J. R. Angiotensin II and the development of insulin resistance: implications for diabetes. Mol. Cell. Endocrinol. 2009;302:128-139.

8. Bertram G Katzung, Anthony J Trevor Katzung, Basic and Clinical Pharmacology 13th Edition, 2015, page no: 185 .

9. Takeda Pharmaceuticals North America. Edarbi prescribing information. 2011.

10. Kohara Y, Imamiya E, Kubo K, Wada T, Inada Y, Naka T. A new class of angiotensin II receptor antagonists with a novel acidic bioisostere. Bioorganic Medicinal Chemistry Letters. 1995;5:1903-8.

11. Kohara Y, Kubo K, Imamiya E, Wada T, Inada Y, Naka T. Synthesis and angiotensin II receptor antagonistic activities of benzimidazole derivatives bearing acidic heterocycles as novel tetrazole bioisosteres. J Med Chem. 1996;39:5228-35.

12. Rakugi H, Enya K, Sugiura K, Ikeda Y. Comparison of the efficacy and safety of azilsartan with that of candesartan cilexetil in Japanese patients with grade III essential hypertension: a randomized, double-blind clinical study. Hypertens Res.; 2012.

13. Naka T, Kubo K. A new class of diacidic nonpeptide angiotensin II receptor antagonists: candesartan cilexetil. Curr Pharm Des. 1999;5:453-72.

14. Baker WL, White WB. Azilsartan medoxomil: A new angiotensin II receptor antagonist for treatment of hypertension. Ann Pharmacother. 2011;45:150615.

15. Neal B, MacMahon S, Chapman N. Blood Pressure Lowering Treatment Trialists' Collaboration. Effects of ace inhibitors, calcium antagonists, and other bloodpressure-lowering drugs: Results of prospectively designed overviews of randomised trials. Blood pressure lowering treatment trialists' collaboration. Lancet. 2000;356:1955-64. 
16. Zannad F, Fay R. Blood pressure-lowering efficacy of olmesartan relative to other angiotensin II receptor antagonists: an overview of randomized controlled studies. Fundam Clin Pharmacol. 2007;21:181-90.

17. Sica D, White WB, Weber MA, Bakris GL, Perez A, Cao C, et al. Comparison of the novel angiotensin II receptor blocker azilsartan medoxomil vs valsartan by ambulatory blood pressure monitoring. The Journal of Clinical Hypertension. 2011;13:467-72.

18. White WB, Weber MA, Sica D, Bakris GL, Perez A, Cao C, et al. Effects of the angiotensin receptor blocker azilsartan medoxomil versus olmesartan and valsartan on ambulatory and clinic blood pressure in patients with stages 1 and 2 hypertension. Hypertension. 2011;57:413-20. 